Originais recebidos em 19/03/2021. Aceito para publicação em 01/08/2021.

Avaliado pelo sistema double blind peer review. Publicado conforme normas da ABNT.

Open acess free available online.

DOI: https://doi.org/10.35700/2359-0599.2022.16.3179

\title{
Minhocário como alternativa sustentável para destinação e transformação de resíduos orgânicos
}

Ana Regina Dahlem Ziech - https://orcid.org/0000-0002-3947-9085 ${ }^{1}$

Erik Vinicius de Freitas - https://orcid.org/0000-0002-8879-8824²

Ana Verônica Martins Lucas Trovó - https://orcid.org/0000-0002-7593-715133

Claudia Matos da Costa Silveira - https://orcid.org/0000-0002-8080-699X ${ }^{4}$

\section{RESUMO}

Por meio de um projeto de extensão desenvolvido por acadêmicos dos cursos de Agronomia e Ciências Biológicas foi realizada uma oficina prática de educação ambiental com o suporte da construção coletiva de um minhocário. 0 objetivo da proposta era de sensibilizar e apresentar aos adolescentes do Centro de Convivência Integral da Criança e Adolescente uma alternativa correta de destinação de resíduos orgânicos domiciliares para que ao invés de serem descartados no lixo comum, esses resíduos pudessem ser transformados em adubo para produção de mudas e utilizados nas plantas da horta. Houve intensa participação do público-alvo, indicando o despertar do senso de pertencimento e satisfação pelo trabalho realizado. Aos acadêmicos a atividade proporcionou o contato direto com a sociedade através da prática extensionista, permitindo uma vivência e experiência diferenciada para a vida pessoal e atuação profissional.

Palavras-chave: extensão; educação ambiental; vermicompostagem.

\footnotetext{
1 Doutora em Agronomia, Professora da Universidade Tecnológica Federal do Paraná - UTFPR, Câmpus Santa Helena. E-mail: anazich@utfpr.edu.br

2 Graduando do Bacharelado em Agronomia pela UTFPR, Câmpus Santa Helena. E-mail: erik50050@gmail.com

3 Graduanda da Licenciatura em Ciências Biológicas pela UTFPR, Câmpus Santa Helena. E-mail: trovo.vee@gmail.com

4 Graduanda da Licenciatura em Ciências Biológicas pela UTFPR, Câmpus Santa Helena. E-mail: qualiyflex.dario@gmail.com
} 


\section{Worm farming as a sustainable alternative for the destination and transformation of organic waste}

Through an extension project developed by academics from the Agronomy and Biological Sciences courses, a practical workshop on environmental education was held with the support of the collective construction of wormery. The purpose of the proposal was to raise awareness and present to the adolescents of the Center for Integral Living for Children and Adolescents a correct alternative for the disposal of household organic waste so that instead of being discarded in the common garbage, these residues could be transformed into fertilizer for the production of seedlings and used in the plants of the garden. There was intense participation of the target audience, indicating the awakening of the sense of belonging and satisfaction with the work done. For the academics, the activity provided direct contact with the society through extension practice, allowing for a differentiated experience for personal life and professional performance.

Keywords: extension; environmental education; vermicomposting.

\section{INTRODUÇÃO}

As elevadas quantidades de resíduos sólidos orgânicos gerados em áreas urbanas, tanto de origem domiciliar quanto de áreas comerciais e industriais, têm representado uma problemática ambiental. Os resíduos orgânicos domiciliares são, muitas vezes, descartados de maneira incorreta, representando uma preocupação ambiental, bem como desperdícios de energia e nutrientes (LOUREIRO et al., 2007; DIÓGENES et al., 2020).

Nesse sentido, o adequado processo de reciclagem, a partir da transformação desses resíduos pela ação biológica realizada por microrganismos (compostagem) ou pela simbiose entre minhocas e microrganismos (vermicompostagem), torna-se uma excelente alternativa, pois afeta positivamente à questão ambiental. Além disso, em contrapartida, resulta em fertilizante orgânico para a agricultura, também chamado de composto orgânico ou húmus que retorna ao solo e ambiente sem causar danos (LOUREIRO et al., 2007; DORES-SILVA; LANDGRAF; REZENDE, 2013).

De acordo com Diógenes et al. (2020), para a construção de um ambiente sustentável é preciso que as pessoas tenham conhecimento, mudança de hábitos e iniciativa para desenvolver em suas casas ações simples como a construção de hortas, 
minhocários e de biodecompositores, por exemplo. 0 minhocário, possui forte potencial como ferramenta para educação ambiental, pois desperta o interesse em pessoas de todas as idades. Ademais, é uma tecnologia simples, de baixo custo e de fácil estabelecimento pela comunidade envolvida (DIÓGENES et al., 2020; MAZAROTTO; SILVA, 2017).

Assim como as escolas, os centros de convivência de crianças e adolescentes também são produtores de grande quantidade de resíduos que em sua maioria são orgânicos. A correta destinação e reciclagem dos resíduos sólidos orgânicos, principalmente dos alimentares, pode ser obtida através do processo simples de vermicompostagem (MAZAROTTO; SILVA, 2017), o qual consiste na transformação pela ação de minhocas e pode ser feito ao ar livre, no jardim e quintal ou, também, dentro de casas e apartamentos (BRITO, 2010).

Nesse sentido, a Universidade Tecnológica Federal do Paraná (UTFPR), Câmpus Santa Helena, através do projeto de extensão "Horta escolar como ferramenta de apoio ao desenvolvimento de crianças e adolescentes em vulnerabilidade social", buscou agregar às ações educativas que vinham sendo desenvolvidas junto à horta do Centro de Convivência Integral da Criança e Adolescente - CCICA, relacionadas às diferentes práticas e etapas de cultivo de hortaliças, uma oficina prática complementar referente a destinação e transformação biológica dos resíduos orgânicos.

Assim, o objetivo deste trabalho foi desenvolver uma oficina prática de educação ambiental com o suporte da construção coletiva de um minhocário, buscando envolver os acadêmicos de graduação em atividades de extensão universitária e sensibilizar e apresentar aos adolescentes do CCICA uma alternativa correta de destinação de resíduos orgânicos domiciliares que ao invés de irem para o lixo comum podem ser transformados em adubo para as plantas da horta.

A oficina prática foi realizada em 06 de dezembro de 2019 com um grupo de 12 adolescentes participantes do CCICA com idades entre 12 e 17 anos do município de Santa Helena. A equipe executora foi constituída por uma professora e seis acadêmicos de períodos distintos dos cursos de Bacharelado em Agronomia e Licenciatura em Ciências Biológicas, e o conteúdo abordado na oficina se relaciona com diferentes disciplinas da grade curricular de cada curso, em especial Agroecologia - disciplina comum para ambos.

Inicialmente, no ambiente da horta foi realizada a contextualização teórica da problemática ambiental do descarte indevido dos lixos domiciliares e repassadas informações técnicas com linguagem adequada ao público-alvo, de modo que houvesse compreensão da atividade e da importância do tema. Para a construção do minhocário junto a horta do CCICA, de forma coletiva e participativa envolvendo os integrantes da equipe executora e os adolescentes participantes da oficina, optou-se por utilizar o 
modelo composto por estruturas simples e de baixo custo denominada "minhocário campeiro" (SCHIEDECK et al., 2007).

A primeira etapa de estruturação do minhocário consistiu na colocação dos bambus, os quais foram intercalados um sobre o outro de forma que as pontas se cruzassem (Figura 1). 0 fundo e as laterais foram forrados com sombrite para conter o húmus, os resíduos alimentares, as minhocas e permitir a adequada drenagem do excesso de umidade.

Figura 1 - Colocação dos bambus intercalados na construção do minhocário

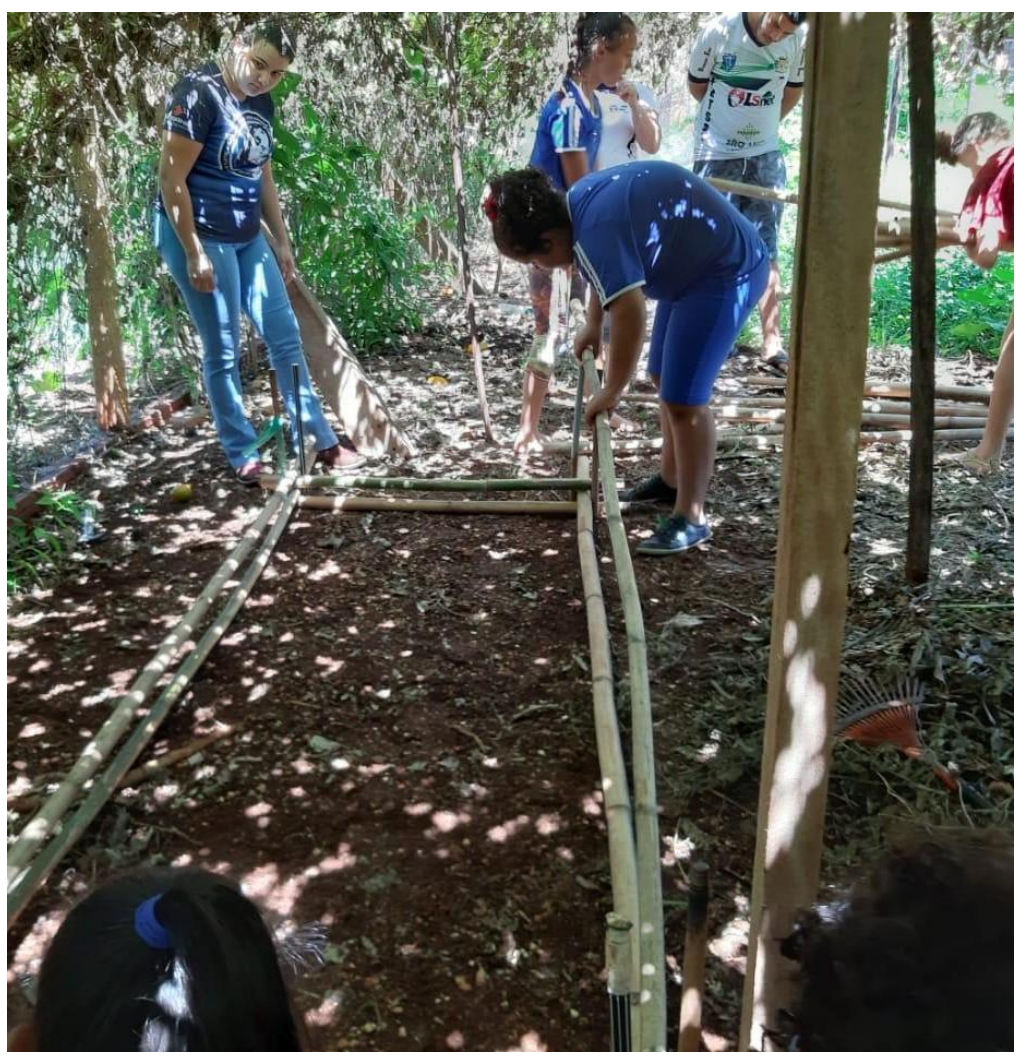

Fonte: Arquivo do projeto.

A segunda etapa consistiu na adição de esterco bovino curtido no fundo do minhocário, formando uma camada entre 10 e $15 \mathrm{~cm}$ como base inicial que abrigaria as minhocas da espécie vermelha da califórnia (Eisenia andrei), adicionadas na sequência (Figura 2.A). Os restos orgânicos da cozinha da instituição (cascas de frutas e legumes, folhas de verduras, casca de ovos, erva de chimarrão, borra de café, entre outros) que haviam sido devidamente separados pelas funcionárias foram depositadas no minhocário (Figura 2.B). 
Figura 2 - A) Adição de esterco bovino curtido e B) resíduos alimentares orgânicos, provenientes da cozinha do CCICA
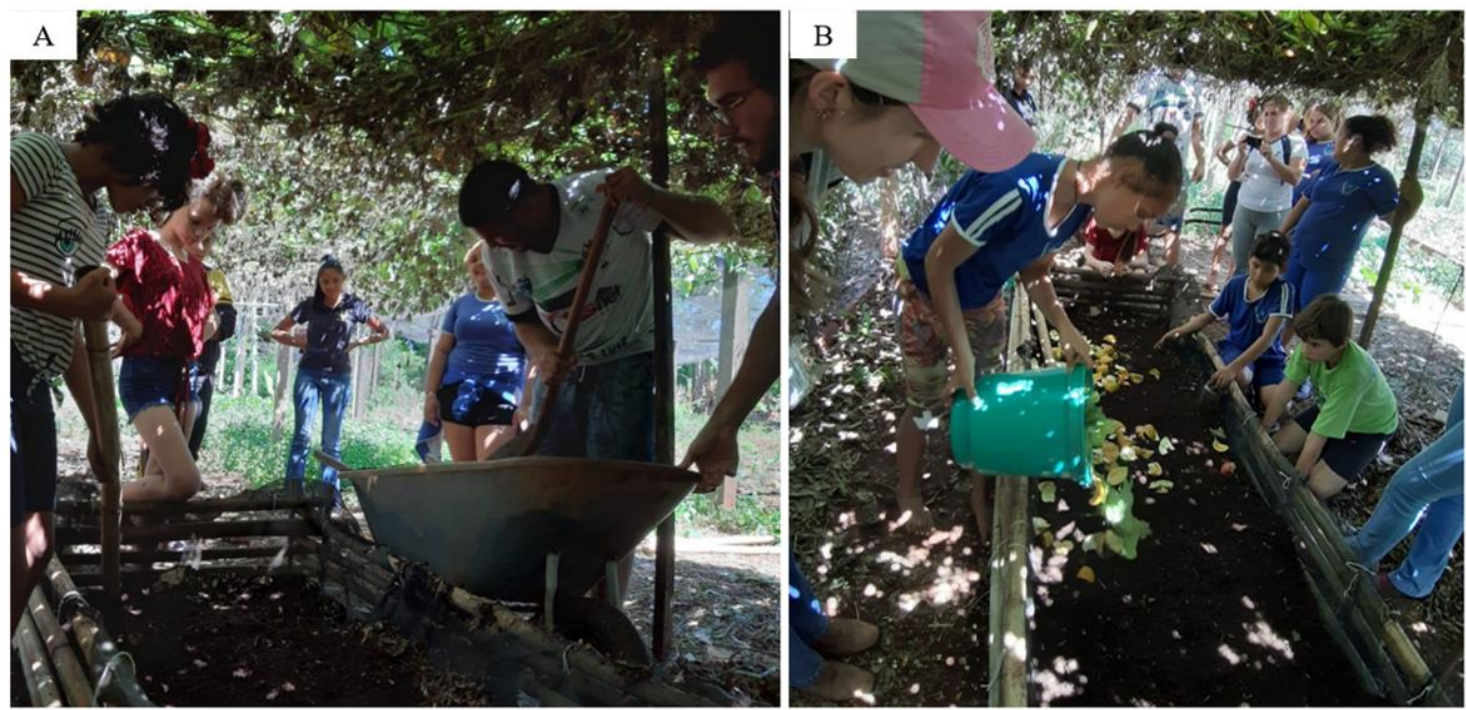

Fonte: Arquivo do projeto.

No momento da adição dos resíduos orgânicos ao minhocário houve uma pausa nas atividades para ressaltar aos participantes as orientações e exemplificações dos tipos de resíduos adequados ao processo que podem ser inseridos sem preocupação (cascas de frutas, legumes e verduras, sementes, chá, borra de café, erva de chimarrão, guardanapos, alimentos cozidos com pouco tempero, folhas secas, grama, serragem, maravalha, entre outros) e aqueles que não podem (lácteos, carnes, gorduras, temperos fortes a exemplo de saladas contendo sal, vinagre ou limão, pimentas, fezes de animais domésticos, entre outros) ser adicionados ao minhocário. Desse modo, evidenciou-se aos adolescentes a importância da separação até mesmo dos resíduos orgânicos para destinação ao minhocário, de forma que ocorra o correto funcionamento do processo de transformação pelas minhocas e, principalmente, que se garanta a sobrevivência delas no local. Para cobertura dos resíduos alimentares e adição de material seco (carbono) ao processo de decomposição, foi depositada uma camada espessa de palha seca, resultante da trituração de folhas e galhos de poda urbana.

A terceira e última etapa da oficina prática consistiu na montagem da estrutura de cobertura e sombreamento do minhocário. Assim como nas outras etapas da atividade, os adolescentes foram motivados a manifestar suas percepções e entendimento sobre a etapa em execução. Nesse momento em especial, os adolescentes foram instigados a buscar possibilidades e alternativas de materiais para cobertura, dentre as manifestações, um dos participantes sugeriu a utilização de folhas de bananeira, material disponível no local de realização da atividade, acessível e de baixo custo (Figura 3. A). 
Figura 3 - A) Cobertura do minhocário com folhas de bananeira apoiadas em varas de bambu e B) minhocário em funcionamento após um ano da atividade
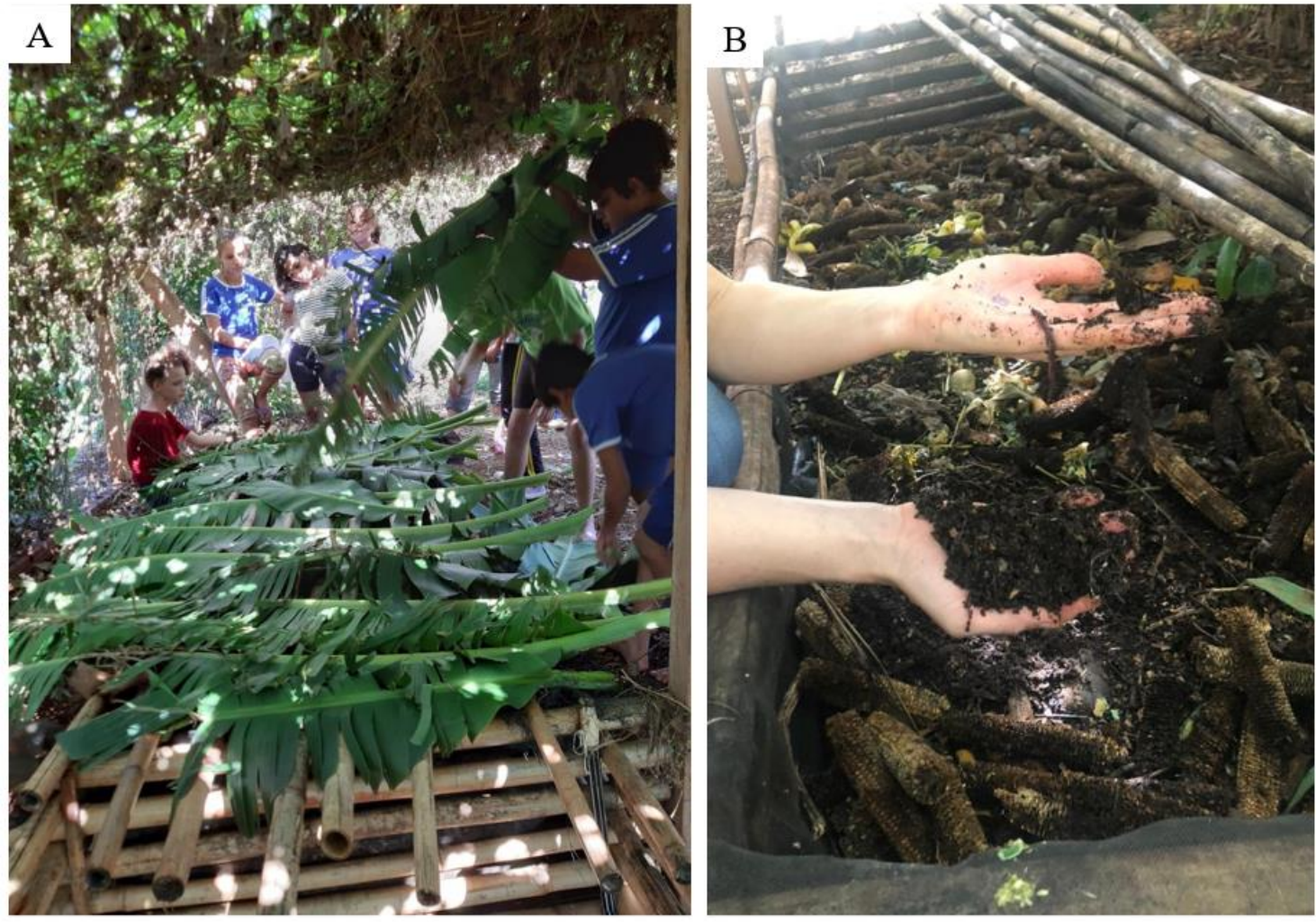

Fonte: Arquivo do projeto.

Ao final, foram ressaltados orientações, procedimentos e cuidados para a manutenção contínua referente à adição dos resíduos alimentares, de forma que as minhocas tivessem um ambiente adequado e para que produto gerado (húmus) tenha a melhor qualidade possível. Cabe destacar que houve intensa participação de todos na ação proposta e espontaneamente os adolescentes prontificaram-se a execução das atividades. Ao longo de toda oficina foram realizadas explicações pontuais das etapas em execução e a sua importância. Ao final, foram realizados questionamentos de forma verbalizada aos grupos participantes, de modo que eles pudessem responder e os demais colegas complementassem as respostas com intuito de averiguar o entendimento e absorção do conhecimento construído. Pode-se perceber que a atividade junto aos adolescentes despertou a atenção e promoveu o entendimento do processo, alcançando assim o objetivo proposto, além de promover o senso de pertencimento e satisfação pelo produto elaborado, gerando a expectativa de que essa prática se multiplique para além da entidade atendida.

Em visita realizada à entidade em março de 2021, constatou-se que passados mais de um ano da realização da oficina e construção do minhocário ele ainda se encontra 
em funcionamento (Figura 3.B), e tem sido utilizado em ações educativas junto às crianças e adolescentes pelos próprios educadores do CCICA.

Através da autoavaliação junto à equipe executora, identificou-se que a realização do trabalho também proporcionou impactos positivos nos acadêmicos envolvidos, uma vez que permitiu a prática extensionista através do contato direto com a comunidade, sobretudo em uma organização social, proporcionando uma vivência diferenciada para a vida e atuação profissional.

\section{REFERÊNCIAS}

BRITO, Danilo. Compostagem e vermicompostagem em escolas de educação básica: uma proposta para educação ambiental. Anais V Congresso de Pesquisa e Inovação da Rede Norte Nordeste de Educação Tecnológica. Maceió, 2010.

DIÓGENES, Aires de Melo et al. Análise de implantação de coleta seletiva nas centrais de abastecimento de Goiás. Brazilian Journal of Development, Curitiba, v. 6, n. 3, p.14927-14935, 2020.

DORES-SILVA, Paulo; LANDGRAF, Maria Diva; REZENDE, Maria Olímpia de. Processo de estabilização de resíduos orgânicos: vermicompostagem versus compostagem. Química Nova, São Paulo, v. 36, n. 5, p.640-645, 2013.

LOUREIRO, Diego Campana et al. Compostagem e Vermicompostagem de resíduos domiciliares com esterco bovino para a produção de insumo orgânico. Pesquisa Agropecuária Brasileira, Brasília, v.42, n.7, p.1043-1048, 2007.

MAZAROTTO, Edson José; SILVA, Cristiane Bezerra da. Vermicompostagem na escola: uma alternativa sustentável para destinação de resíduos sólidos orgânicos. Visão Acadêmica, Curitiba, v.17, n.1, 2016.

SCHIEDECK, Gustavo et al. Minhocário campeiro de baixo custo para a agricultura familiar. Comunicado Técnico 171, Pelotas: Embrapa, 2007.

Os autores declaram participação na autoria conforme a Taxonomia CRediT da Casari (vide https://casrai.org/)

\begin{tabular}{|c|c|c|c|c|c|c|}
\hline Conceituação & Metodologia & Software & Validação & Análise formal & Investigação & Recursos \\
\hline$[1] /[2]$ & {$[1] /[2] /[3] /[4]$} & & & {$[1]$} & {$[1] /[2] /[3] /[4]$} & \\
\hline Curadoria & Primeira redação & Revisão/edição & Visualização & Supervisão & Admin. projeto & Financiamento \\
\hline & {$[1] /[2]$} & {$[1]$} & & & & \\
\hline
\end{tabular}

